\title{
Al-Li-Mg-Sc (Aluminum-Lithium-Magnesium-Scandium)
}

\section{Raghavan}

An isothermal section at $400{ }^{\circ} \mathrm{C}$ and at $0.2 \mathrm{mass} \% \mathrm{Sc}$ was determined by [1993Fri] for this quaternary system.

\section{Lower Order Systems}

The phase diagrams of the constituent binary systems can be found in [Massalski2]. The $\mathrm{Al}-\mathrm{Li}-\mathrm{Mg}$ system was updated by [2005Gho]. The Al-Li-Sc system is reviewed in this issue. The Al-Mg-Sc system was updated by [2007Rag].

\section{Quaternary Phase Equilibria}

With starting metals of $99.99 \% \mathrm{Al}, 99.8 \% \mathrm{Li}, 99.96 \%$ $\mathrm{Mg}$, and $99.986 \% \mathrm{Sc}$, [1993Fri] melted alloys in a resistance furnace under the cover of a flux. The alloys were annealed at $400{ }^{\circ} \mathrm{C}$ for $200 \mathrm{~h}$. The phase equilibria were studied by $\mathrm{x}$-ray powder diffraction and optical and transmission electron microscopy. The phase compositions were measured with $\mathrm{x}$-ray spectral analyzer attached to a scanning electron microscope. The isothermal section constructed by [1993Fri] at $400{ }^{\circ} \mathrm{C}$ and at 0.2 mass $\% \mathrm{Sc}$ is shown in Fig. 1. The Al-Li-Mg ternary compound $\mathrm{Al}_{2} \mathrm{MgLi}$ (cubic, $a=2.031 \mathrm{~nm})$ is in four-phase equilibrium with (Al), $\mathrm{ScAl}_{3}$ and AlLi.

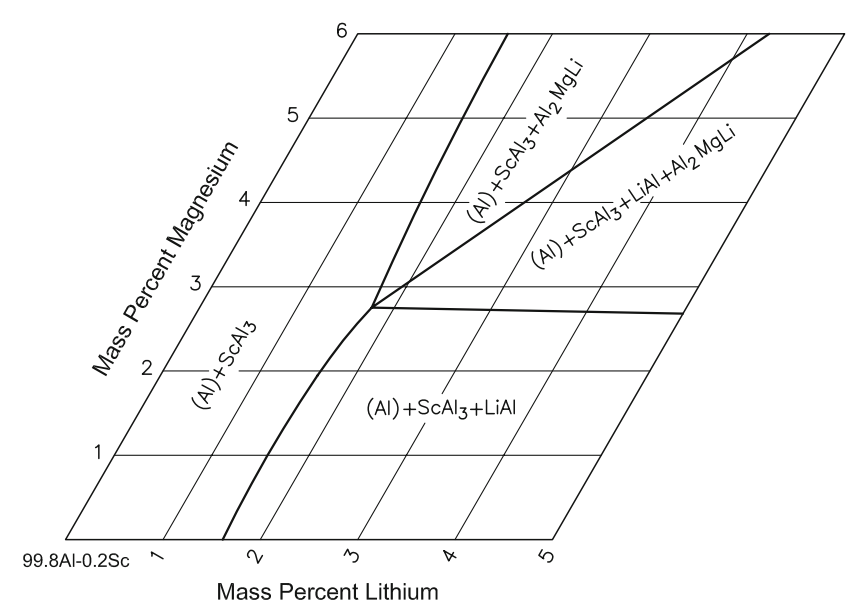

Fig. 1 Al-Li-Mg-Sc isothermal section at $400{ }^{\circ} \mathrm{C}$ and at 0.2 mass\% Sc [1993Fri]

\section{References}

1993Fri: I.N. Fridlyander, L.L. Rokhlin, and T.V. Dobatkina, and N.I. Nikitina, Investigation of the Phase Equilibria in Aluminum Alloys Containing Lithium. Metallovedenie Term. Obrab. Metallov, 1993, (10), p 16-19, in Russian; TR: Metal Sci. Heat Treatment, 1993, (10), p 567-571

2005Gho: G. Ghosh, Aluminum-Lithium-Magnesium, LandoltBornstein Series IV, 2005, (11A3), p 93-108

2007Rag: V. Raghavan, Al-Mg-Sc (Aluminum-MagnesiumScandium), J. Phase Equilb. Diffus., 2007, 28(5), p 471-472 